\title{
The intersection of pop culture and non-traditional sports: an examination of the niche market of quidditch
}

\section{Adam Cohen*, Brandon Brown and Jon Welty Peachey}

Department of Health and Kinesiology,

Texas A\&M University,

4243 TAMU, College Station,

TX, 77843-4243, USA

Fax: 1-979-862-4428

E-mail: ascohen@hlkn.tamu.edu

E-mail: bbrown@hlkn.tamu.edu

E-mail: jweltypeachey@hlkn.tamu.edu

*Corresponding author

\begin{abstract}
The real sport of quidditch was recently adapted from the fictional sport of the same namesake in the Harry Potter (HP) franchise. Quidditch is played at hundreds of locations across the USA and around the world. Considering the lack of marketing research on non-traditional, co-ed sports and the innovative nature of quidditch, the purpose of this research was to conduct a qualitative, grounded theory study (Strauss and Corbin, 1990) on the athletes and determine how involvement and identification is associated with these individuals becoming a viable niche market within the sports industry. Five factors led towards a desire to partake in quidditch and become involved and identified with the sport: identification with Harry Potter, camaraderie and friendship, desire to have fun, desire to try something new, and desire to get in shape.
\end{abstract}

Keywords: non-traditional sport; niche sport; psychosocial involvement; social identification; quidditch; Harry Potter; grounded theory; player motivation.

Reference to this paper should be made as follows: Cohen, A., Brown, B. and Welty Peachey, J. (2012) 'The intersection of pop culture and non-traditional sports: an examination of the niche market of quidditch', Int. J. Sport Management and Marketing, Vol. 12, Nos. 3/4, pp.180-197.

Biographical notes: Adam Cohen is a third-year doctoral student and research assistant at Texas A\&M University. Before returning to graduate school, he was involved in advocacy initiatives in the non-profit community for six years including a year of service with Americorps VISTA. His research is focused on the field of sport-for-development and social justice initiatives with sport components, as well as on non-traditional sports and their impact on participants.

Brandon Brown is a Sport Management doctoral student at Texas A\&M University. After receiving his Bachelor's degree in Sport Management at Florida State University, he went on to receive both a Master's degree in Business Administration and Sport Business Management. Before attending Texas A\&M University, he worked as a Sales Associate for the New York Mets in Queens, New York. His current line of study focuses on sport marketing. 
Jon Welty Peachey is an Assistant Professor of Sport Management at Texas A\&M University. His research centres upon sport for social change and development, organisational change, and developing effective and inclusive leadership strategies for sport organisations. He has over 12 years of experience working in the international sport context, including serving as vice president of international operations with the Institute for International Sport, a worldwide non-profit organisation using sport to effect positive social change.

\section{Introduction}

Based on the fictional sport of the same namesake in the Harry Potter (HP) franchise created by J.K. Rowling, a live version of quidditch was founded in 2005 at Middlebury College in the USA. Currently, over 350 collegiate, high school, and community teams have formed around the world with over 1,000 more in various stages of creation (IQA, 2011). The sport's non-profit governing body, the International Quidditch Association (IQA), currently touts this mandatory co-ed sport as one of the most inclusive, socially engaging and competitive in the world. Due to the dearth of marketing research on non-traditional, co-ed sports and the innovative nature of quidditch, the purpose of this research was to conduct a qualitative, grounded theory study (Charmaz, 2005; Strauss and Corbin, 1990) on the athletes to determine how motivation and involvement are associated with participants becoming a viable market in the sports industry. This study addresses a gap in the literature and illuminates a new demographic of athletes worth considering in the sports marketing field. Determining causes for participation in the sport can help identify factors relevant to targeting niche markets and the consumer intentions that coincide.

While grounded theory is not a common methodology used in marketing, several researchers have utilised its ability to explore occurrences in the field (Goulding, 1998; Hirschman and Thompson, 1997; Houston and Venkatesh, 1996). Goulding (2001, p.32) supported the use of grounded theory in marketing due to its "fundamental procedures [which] offer a systematic method for handling and analysing data...[this] may lead to innovative new perspectives". This technique allowed the researchers to fully immerse themselves within the sport of quidditch and its participants. As the sport has never been empirically examined, and because full contact, co-ed activities have been subject to limited research, the exploratory nature of grounded theory was deemed most favourable for the current study.

\section{Research context}

Real life quidditch is a full-contact sport that combines aspects of rugby, dodgeball, and tag. The major components of the sport involve throwing 'bludgers' (rubber dodgeballs) at opponents, scoring goals by tossing 'quaffles' (a slightly deflated volleyball) through one of three hoops, and attempting to catch the 'snitch' (a human dressed in yellow with a flag or sock hanging from his or her waist) to end the game. This all happens with one hand, while the other is occupied with holding a broom between one's legs upon which the athletes must constantly remain mounted. The game combines athleticism and 
whimsy and seemingly has appeal for individuals looking to try something new and different from traditional sports. Another major rule in the sport, which differs from other contact sports, is the mandatory co-ed requirement. At all times there must be a gender ratio of at least five to two (i.e., five males and two females on the field or vice versa).

A common line of research in the field of sports marketing involves the analysis of a sporting occurrence and evaluating its impact on a person's spending habits (Gladden and Sutton, 2009; Arnett and Laverie, 2000). With regard to quidditch, this seems to be a rare instance where a product of pop culture leads to sport participation. In other words, the product promotes the sport in lieu of sport promoting the product. Value can be established in examining this niche market due to the rare combination of both an affinity towards sports and the HP franchise.

\section{Literature review}

The following section draws on the literature regarding the influence motivational factors and psychosocial involvement can have on a person's decision to take part in and identify with a sport. It also reviews niche sport influence in the sports marketing field.

\subsection{Motivation to play sport}

Motivation has often been recognised as a crucial component of an athlete's desire to participate in sports and exercise (Gould et al., 2002; Wilson et al., 2008). One aspect this research has focused on is the intrinsic and extrinsic nature of motivation (Deci, 1971; Vallerand, 2007). Intrinsic motivation focuses on the self-satisfaction derived from participation, motivations to achieve accomplishments, and experience stimulation (Vallerand, 2007; Vallerand et al., 1989), while extrinsic motivation refers to taking part in an activity as a means to an end. Extrinsic motivation is often associated with rewards and external pressures (Deci and Ryan, 1985; Vallerand, 2007). In particular, Vallerand (1997) designed a hierarchical model of intrinsic and extrinsic motivation (HMIEM) in an effort to further explain these two motivational outlets. The author recommended future research to be framed in line with HMIEM to create comprehensive perceptions of the psychological processes underlying motivational trends that occur in sport (Vallerand, 2007).

Sport motivation research is often associated with sport participation and dropout behaviour (Fraser-Thomas et al., 2008; Gould, 1987; Roberts, 2001). Gould and Horn (1984) concluded that children withdraw from sport for varied reasons, such as conflicts of interest, lack of playing time, lack of success or improvement, lack of fun, dislike of the coach, boredom, and injury. Other scholars identified additional intrinsic and extrinsic factors for participating in sport such as fun, health, competitiveness, and appearance (Coakley, 2001; Skill and Osteras, 2011). Gould (1987, p.80) built on those findings and suggested, "When these motives are not achieved, children weigh the costs versus benefits of participation and often withdraw". Getting people to participate in organised sport is a greater challenge than ever before due to a plethora of distractions (i.e., television and video games) enabling individuals to stray from sport participation. While the visual of seeing people on quidditch teams run around on brooms might seem bizarre at first glance, these unique aspects may serve as motivation for those who normally would avoid places like the football field or baseball diamond. Additionally, these unique 
aspects of niche sports could help fulfil intrinsic motivations (Vallerand, 2007) and prevent potential athletes from completely withdrawing from sport participation. The more prospective avenues for enthusiasm towards physical activity and team sports are cultivated, the more likely people will become drawn in and receive the benefits. In an effort to prevent dropout, Riewald (2003) suggested that organisers purposefully incorporate fun into the training environment, integrate social interaction, and mandate variety. Each of these factors focuses on intrinsic motivations and deemphasises external rewards and outcomes.

Taking part in quidditch could potentially impact an individual's identification, another intrinsic motivational factor. Social identity theory posits individuals will categorise themselves and others in terms of social groups such as race, sex, and religion (Tajfel and Turner, 1986). When an individual identifies with a particular group, he/she typically feels a sense of belonging to the group (Ellemers et al., 2002). Furthermore, individuals use their social identities to help navigate their social world. Specifically, the norms, beliefs, and behaviours of the group act as a guide for how the members should act and respond to certain events. Consequently, when an individual is highly identified with a group, he/she will tend to emulate the actions of the group (Hewstone et al., 2002). This phenomena is particularly relevant for the study at hand, for when a group (in this case, grassroots sport athletes, or fans of HP) migrates towards quidditch, more individuals who see themselves as part of the group will be apt to follow the same path.

\subsection{Involvement (and quidditch consumption)}

Involvement in sport has garnered significant interest from sport marketers and practitioners alike (Bennett et al., 2009; Kim et al., 1997). Involvement is a multifaceted concept that encompasses consumers' cognitions and psychological commitments (Kerstetter and Kovich, 1997). In addition to its influence on significant reference group members, involvement also influences sociological attachment (Milne and McDonald, 1999; Wakefield, 1995). Research has demonstrated a correlation between involvement and commitment, spectatorship, and high levels of consumption (Funk et al., 2004; Iwasaki and Havitz, 1998). Due to the fact that involvement has recently been conceptualised in a social-psychological sport setting, Armstrong (2002) has labelled the construct as 'psychosocial sport involvement'.

Bennett et al. (2009) claimed psychosocial sport involvement describes the level that a person is really 'into' a sport. In the current study, psychosocial sport involvement describes the level a consumer values or believes that quidditch is a notable component to his or her life and lifestyle. Within psychosocial sport involvement, the literature identified several types of involvement, specifically enduring involvement and behavioural involvement (Day et al., 1995; Richins et al., 1992). Enduring involvement is often linked to motivation, arousal, or interest towards an activity or sporting event (Havitz and Mannell, 2005). Richins et al. (1992) indicated involvement is also associated with behavioural constructs. Behavioural involvement entails actions such as acquiring information or actual participation (Stone, 1984). Thus, the degree to which consumers are psychosocially involved with a sport not only affects their overall sport consumption habits, but will also influence their social desires. Being that quidditch participation rates have grown (IQA, 2011), this suggests participants have significantly increased involvement levels. Consequently, an increase in social and psychosocial involvement levels with quidditch will likely influence social desires. 


\subsection{Niche sport marketing}

While current marketing research on quidditch is non-existent, studies have been conducted on involvement with niche sport marketing (Bennett et al., 2002, 2009). Several studies revealed the advantages of marketing niche sports in comparison to mainstream sports. For example, Milne et al. (1996) found that sport corporations are likely to participate in niche sports sponsorship activities due to the perception that they provide cost effective sponsorship opportunities. Other investigations suggested that niche sports can thrive in various markets due to their ability to differentiate from other sports (Andrew et al., 2009; Kim et al., 2009). In respect to this differentiation aspect, Greenhalgh et al. (2011, p.48) stated, "Niche sport marketers who can focus on promoting these unique attributes will be more successful in attracting and retaining fans". Furthermore, Greenhalgh et al. (2011) maintained consumers value niche sports due to affordability and an aptitude to relate to the sport due to a sense of perceived similarity between the sport and themselves. This is of particular interest to the current study, as the target fan base encompasses individuals who make up the massive following of the HP franchise, and thus already convey a sense of similarity with the sport. Further to this point, Miloch and Lambrecht (2006) stated a consumer's lifestyle directly influences purchasing decisions, particularly when consuming niche sports.

According to Mulin et al. (2007), the goal of any product in its first lifecycle phase should be to garner awareness and stimulate trial amongst consumers who are willing to test new products. Members in the 14-31 year old range, or the generation Y demographic (Noble et al., 2009; Paul, 2001), are considered desirable consumers due to active spending habits in the marketplace. One example of a specific demographic of athletes and their fans that was analysed from a marketing perspective is the action sports industry (Bennett and Lachowetz, 2004; Dees et al., 2010). The investigation of such sports like surfing, skateboarding, and BMX biking allowed targeted marketing strategies to be developed. These strategies led to an effective sponsorship with Mountain Dew, which believed its brand to be a viable fit for the demographic (Dees et al., 2010). Other prominent companies have also taken advantage of niche sport marketing, such as Red Bull's signature air event competition, the 'Red Bull Flugtag', and Afflication's involvement with the Ultimate Fighting Championship (Kim et al., 2008). In a similar fashion, the sport of quidditch could reach an untapped market segment that could also lead towards successful partnerships and marketing opportunities.

\section{Methodology}

This grounded theory study is part of an on-going partnership formed with the IQA in an effort to monitor and evaluate the non-traditional, co-ed sport of quidditch. For the current study focusing on the athletes' motivations and involvement, the exploratory nature of grounded theory allowed for full immersion within the data in an effort to determine impact of the phenomena being investigated (Charmaz, 2006; Strauss and Corbin, 1990). As part of the approach, open, axial and selective coding (Strauss and Corbin, 1990) was utilised to achieve the development of themes and finalise the dimensions that represent the findings.

To fully investigate the sport, a four-step process (gathering background information, distribution of an online survey, conducting focus groups, and attending the 2011 
Quidditch World Cup) was employed in an attempt to remove researcher bias, increase trustworthiness of the study, and provide a means for triangulation of the information gathered (Lincoln and Guba, 1985). Additional collaboration and discussion of findings occurred between authors to further validate the findings.

\subsection{Gathering background information}

As quidditch was only recently inaugurated, extensive efforts were made to become fully aware and highly knowledgeable about the game and its players. This included observation of social media outlets (i.e., IQA forums, Facebook, and Twitter), reviewing newspaper articles on the sport, viewing YouTube videos of past tournaments, reading the rulebook, and observing local teams at a Southwest University. Memos were recorded throughout this initial exploratory research in an effort to fully process all information available and begin determining initial impact and relevant themes to further explore. Additionally, informational meetings took place between the first author and IQA leadership in order to understand the mission and objectives for the sport.

\subsection{Distribution of open-ended survey}

An online qualitative survey was distributed to participants of the sport in which 343 responses were received (see Table 1 for demographic information). The majority of respondents went to high school or college. Additionally, while most of the respondents had participated in sports in their childhood, over half had quit by the time they reached high school and an even greater majority dropped out in college. Informed by the literature, open- ended questions were chosen to allow respondents to fully express their opinions rather than be forced to make a choice (Foddy, 1993). Open-ended questions also reflected the exploratory nature of grounded theory methodology. A survey link was posted on the IQA's social media outlets (i.e., IQA listserv, Facebook and Twitter) where all players were invited to respond. All survey responses were anonymous.

Table 1 Survey participant demographics

\begin{tabular}{lcc}
\hline Survey participants & Male & Female \\
\hline Total survey respondents: & $149(43 \%)$ & $197(57 \%)$ \\
Age: & $17(11 \%)$ & $30(15 \%)$ \\
$13-17$ & $108(72 \%)$ & $140(71 \%)$ \\
$18-21$ & $17(11 \%)$ & $18(9 \%)$ \\
$22-24$ & $7(5 \%)$ & $8(4 \%)$ \\
$25+$ & & \\
Level of organised sport quidditch players participated in: & $8(5 \%)$ & $27(14 \%)$ \\
Never played an organised sport before quidditch & $120(81 \%)$ & $137(70 \%)$ \\
Youth sports & $74(50 \%)$ & $81(42 \%)$ \\
High school varsity & $49(33 \%)$ & $8(4 \%)$ \\
College club/intramural & & \\
\hline
\end{tabular}


To assess player motivations and involvement, the survey consisted of open-ended questions such as:

a 'How did you find out about your quidditch team?'

b 'What motivated you to join a quidditch team?'

Additional questions focused on participants' identification with the HP franchise were also included (see Table 2). Respondents were given two weeks to fill out the online survey before it was closed, and a reminder notice was deemed unnecessary due to the amount of responses received.

Table 2 Identification with HP franchise

On a scale of 1-7 what kind of fan of the HP brand would you consider yourself to be?
(1: 'minimal fan', 7: 'passionate fan' - I consume all the HP
content I can and still spend money on the product) $N=343$

\subsection{Conducting focus groups}

Initial open coding of the data from the surveys revealed raw data themes which assisted in developing further questions utilised in three focus groups. One focus group was conducted with members of the quidditch team at a Southwest University in the USA, while the other two were conducted online with quidditch players who were selected to obtain a wide representation of individuals in regards to gender, age (16-24) and geographic location (representation from five different regions throughout the USA).

All focus groups consisted of four to eight participants, a number recommended by Krueger and Casey (2009), and were conducted by the first author. To protect confidentiality, study participants were given a pseudonym. The focus group interview guides were semi-structured and based upon the initial findings from the surveys and direct observations. Topical areas, in regards to motivations and involvement, entailed asking participants about their desire to take part in the sport, financial costs and fundraising efforts. Three focus groups were deemed sufficient due to data saturation being achieved through redundancy in themes and information (Creswell, 1998) and the similarity of focus group comments with those obtained from survey questions.

\subsection{Attendance at the 2011 Quidditch World Cup}

Lastly, the annual World Cup hosted by the IQA was attended and observed by the first author. This tournament took place in New York city during November, 2011, and was attended by 93 college and high school teams comprising over 1,600 players from 27 US states as well as Canada, Finland, and Iceland. According to the IQA (2011), over 
11,000 fans attended the event on day one. The first author monitored over 30 matches and additional information was gathered on the marketing aspect of the event such as ticket sales, vendors, and merchandise availability in an effort to supplement qualitative data. Field notes were compiled and used to reinforce other data collection methods.

\subsection{Data analysis}

Throughout these four steps, data were continuously analysed via open (raw data themes), axial (first-order themes) and selective coding (general dimensions) in an effort to define this niche market (Strauss and Corbin, 1990). Nvivo9 software was utilised by the first author who went line by line through the transcripts, field notes and memos in an effort to identify emerging views which were reviewed by the second and third authors to enhance the dependability of the findings. This coding process allowed for the development of significant results and the finalisation of the themes presented below. Using this coding, quotations from participants and observations from the field, illustrating the themes that emerged, were identified. Member checks with study participants were also conducted to increase credibility of the results. Study participants reviewed their transcripts and interpretations, and none of the participants responded with any issues or concerns about their responses.

\section{Findings}

The central research question aimed to evaluate the reasons people decided to participate in quidditch. By gaining further knowledge on the reasoning behind playing this sport, we can therefore define this niche market's motivations for participation. Five factors emerged that led towards a desire to partake in quidditch and become involved and identified with the sport: identification with HP, camaraderie and friendship, desire to have fun, desire to try something new, and desire to get in shape. These themes are presented below utilising quotes drawn from both the online surveys and focus groups (see Table 3 for additional representative quotations for the five factors).

\subsection{Identification with $H P$}

The first and strongest factor influencing motivation and involvement with quidditch was that a large percentage of participants initially became aware of the sport through their appreciation of and identification with the HP franchise. Over $80 \%$ of players noted they were fans to a higher than average degree (see Table 2). A typical response involved players stating that the sport was a way to keep the franchise in their lives. For example, one college player shared, "I love Harry Potter and have been reading the books since Kindergarten, so the idea of a quidditch team basically made my entire life dream come true".

In a similar vein, another player commented:

"I love how quidditch brings a physical nature to the Harry Potter universe, and allows you to be physical while still retaining your inner geek. Everyone feels they can play quidditch because there is no pressure, just a love of Harry Potter and a desire to get on the field." 
Table 3 Quotes, themes, and dimensions generated from data collected

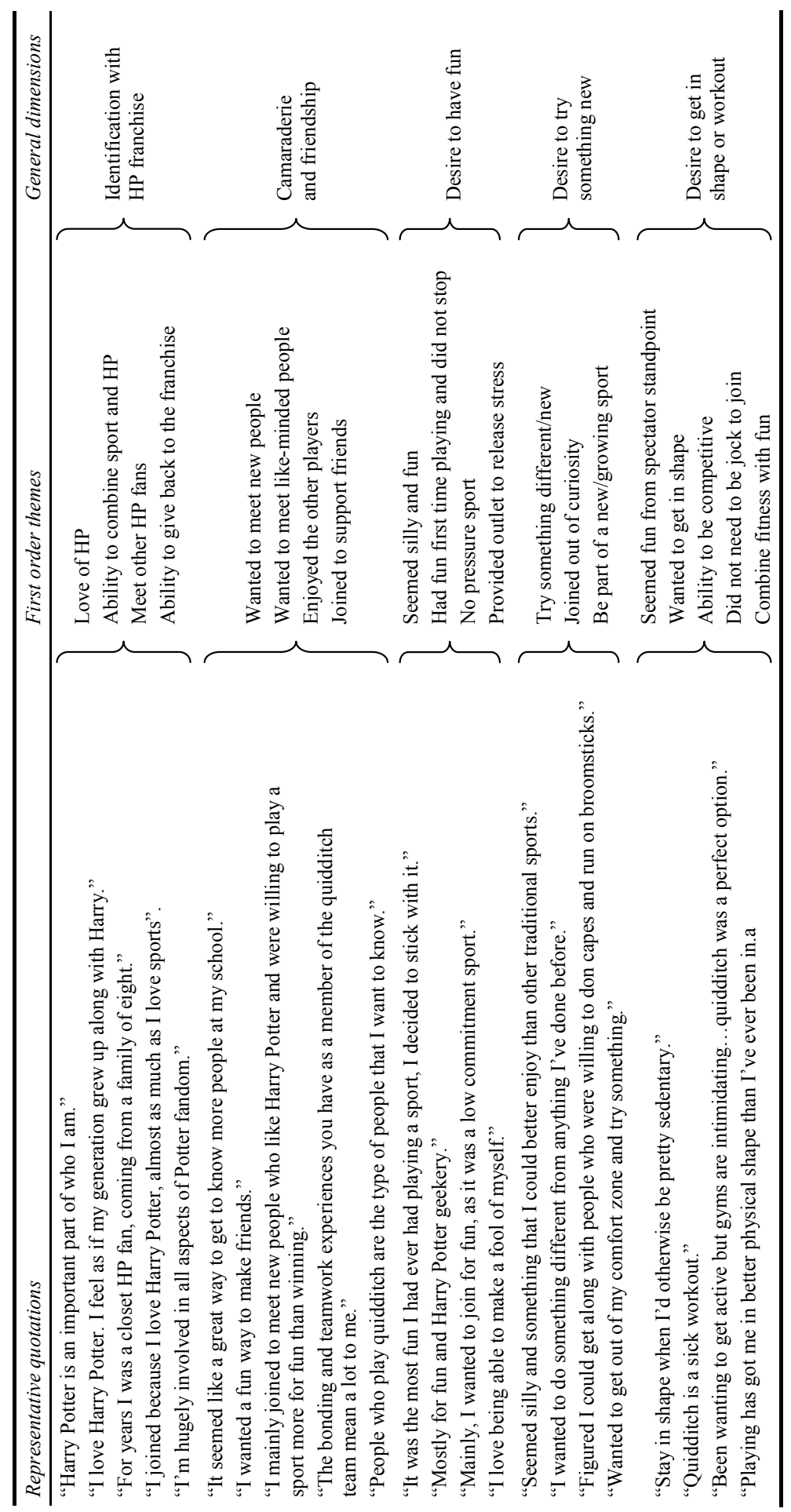


A lifelong fan remarked how the sport allowed her to continue her fandom: "The second I looked it up I knew it had to be in my life. I'm a huge fan of the books, and there's nothing like using quidditch practice as an excuse not to do homework!" Another related response came from a high school senior on her passion for the HP franchise: "I have an obsessive love for Harry Potter and would participate in anything that is Harry Potter related".

Many HP-related theme events were also noted and observed on team Facebook pages and Twitter postings. Beyond participating in the sport itself, teams often gathered for events such as Yule Balls (dances that occurred in the books), movie nights (many teams went as a group for the release of the final HP movie) and costume parties. Creative T-shirt themes were also common, as teams used them both as a means of fundraising and as a way to further promote the HP franchise. Slogans and T-shirts were commonly seen at the World Cup and throughout teams' web pages and were often used as tools for promotion and fundraising, or just a way to show off team pride.

As exemplified in the above quotes and in Table 3, the HP franchise was a significant aspect of many participants' lives, and their partaking in quidditch allowed that passion to continue and even heighten. Their psychosocial involvement with the sport provided an opportunity to keep this enthusiasm in their lives in a completely different way than re-reading the books or watching the movies.

\subsection{Camaraderie and friendship}

The social aspect of the game was a strong intrinsic motivator in getting people involved. Many of the participants sought out peers that fit their self-proclaimed mindset of being 'nerdy' or 'quirky', while others thought participating in a sport would be a good way to meet people. One player commented on people involved, stating, "Other types of activities had not provided me a group of friends that stuck together; I thought that those who loved Harry Potter enough to try such a silly and fun endeavour would be my type of people".

A similar response came from a West Coast quidditch athlete who believed the sport would lead to meeting like-minded people:

"I wanted to do something fun, quirky, and sports-like. I thought the quidditch team would be the right combination of sports, nerdiness, and Harry Potter fans... they became a source of friendship and camaraderie."

Another college student noted she felt like an outsider at her university until she became motivated to create a team from scratch:

"I don't drink or 'party' in college, which is a really big deal at my university, and I felt sort of left out. I was looking for friends who were like-minded, fun, spontaneous, and unashamed about their geekiness, so I started the quidditch team."

From these findings it would appear that quidditch players were motivated to take part in the sport due to quidditch's ability to provide a social outlet other sports could not fulfil. This could suggest the sport has potential, because of its ability to foster new relationships, to reach young people who normally would not partake in a contact sport. 


\subsection{Desire to have fun}

The third intrinsic factor influencing motivation and involvement was that quidditch provided a 'fun' or 'silly' way to play a team sport. While many participants wanted athletics and teamwork in their lives, they had often been turned off to many aspects of traditional sports. Quidditch was able to fulfil a desire other sports could not. For example, one student in the Southwest raved about the sport's ability to satisfy her craving for good time: "I love doing weird, outlandish and wild things. Quidditch is the funniest sport I've ever played".

Similarly, another player in the Northeast simply thought the sport suited his personality, relating, "Being super dorky and loving the books, I thought playing quidditch would be an awesome way to be even dorkier". One college player also suggested the aspect of fun was a strong motivator for involvement: "It was a different sport, something that seemed silly and fun and something that I could better enjoy than most other traditional sports". Another participant noted quidditch was an excellent combination of athletics and whimsy: "Quidditch just sounded like a lot of fun. A way to be competitive and physically active, but also goofy and didn't take itself too seriously. The perfect mix of sports and nerdiness".

These participants further the notion that their motivation and involvement was influenced by quidditch providing a fun outlet other traditional sports could not fulfil.

\subsection{Desire to try something new}

Many players decided to "give it [quidditch] a try" in an effort to attempt something new and exciting. Most of the respondents related the game was addicting, and many even shared it was life changing. One such player from the West Coast commented on how he embraced the game and culture: "I joined with the intention of just trying it for the sake of saying I had played quidditch, and I've been playing ever since". Another player from the Midwest talked about how dynamic the game appeared, sharing, "It looked insane. I figured if I could tackle people and throw balls at their faces WHILE running around with a cape and broomstick, this was the game for me".

A freshman college male from the Northeast was also attracted to the sport due to how different and interesting it seemed:

$$
\begin{aligned}
& \text { "Watching it, I became really excited because I have never seen a sport like it. } \\
& \text { It was a combo of many sports I love like basketball, soccer, dodgeball, and } \\
& \text { handball. So I thought I would give it a try." }
\end{aligned}
$$

While the game had many recognisable aspects to traditional sport such as scoring goals, tackling, and throwing balls at each other, it also had the obvious differences like running around on a broom and competing in a co-ed environment that seemingly appealed to the majority of players.

\subsection{Desire to get in shape or workout}

Finally, quidditch provided an athletic outlet for many people who had little to no interest in playing sports or being physically active. One such player from the West Coast commented on how he never considered playing a team sport: "The fact that you know... I'm getting exercise. I'm possibly the least likely to join a sports team other than 
quidditch on the planet". Another woman raved about how the silliness of the game increased her desire to participate and become active:

"I also found the physical exertion, of which there was surprisingly a lot, to be enjoyable. Running around with a broom between your legs doesn't seem that great, but it is more fun and entertaining than I could have ever imagined."

Another male college player from the Midwest discussed how this sport gave him an outlet to remain active without having to be involved with a traditional sport: "I wanted to do something to stay in shape without being on a traditional sports team. This was a way to combine my love for Harry Potter with physical fitness, it's perfect".

Not only did young athletes comment on how their involvement with the sport caused them to become physically active, they also discussed how the sport motivated them to invest time and money towards physical fitness. Many never imagined they would spend their paychecks (or volunteer time fundraising) to fly cross-country and play a game where they run around on a $\$ 40$ broom. One athlete at the Quidditch World Cup joked about how his Mom would never believe he waited in line for over 30 minutes to purchase a transformed household cleaning product. Another female player mentioned that "this was the first pair of cleats she ever owned".

Thus, quidditch appeared to reach and motivate a demographic of participants who potentially would not have taken part in a traditional team sport or perhaps any type of physical activity.

\section{Discussion}

The purpose of this research was to conduct a qualitative, grounded theory study (Charmaz, 2005; Strauss and Corbin, 1990) on quidditch athletes and determine how motivation and involvement are associated with these individuals becoming a viable market within the sports industry. This furthered previous literature indicating various motivational factors can drive participation in sport and that involvement is correlated with social needs (Bennett et al., 2009; Vallerand, 2007). Accordingly, our study not only reemphasises previous literature on involvement and desires, but also reveals new findings.

Figure 1 provides a conceptual model which illuminates the niche market of quidditch players and motivations the sport seemingly satisfies, which subsequently drives participation (Fraser-Thomas et al., 2008; Gould, 1987). As depicted, there are five factors that influence an individual's psychosocial involvement with, and motivation to participate in, the sport of quidditch, with the strongest being identification with HP. This aligns with findings from Armstrong (2002), who found that the salience of identity will influence involvement. Desire for camaraderie and friendship, desire to have fun, desire to try something new, and desire to get in shape are all factors associated with involvement levels, satisfying several intrinsic motivations known to influence sport participation (Vallerand, 2007; Vallerand et al., 1989). These motivations were not satisfied in other sport environments, which led many participants in this study to dropout and withdrawal from traditional sport participation (Gould and Horn, 1984). Additionally, using quidditch to appease those desires helped fulfil participants' social identity needs (Ellemers et al., 2002), which led them to become identified with the sport. 
Figure 1 also illustrates how many of the participants indicated participating in quidditch allowed them to form a deeper commitment to the HP franchise. This lifestyle, which coincides with passion towards the HP franchise, is important. Miloch and Lambrecht (2006) stated that lifestyle, particularly in niche sports, is directly associated with a will to consume and participate in sports. As the participants displayed a heightened passion towards HP, their sense of involvement with the sport amplified and provided a new way to further their identification and consumerism towards the HP franchise. This cyclical relationship is unique due to the pop culture aspect of quidditch and builds on the suggestion that social identity can be drawn from extracurricular activities such as sport participation (Tajfel and Turner, 1986).

Figure 1 Conceptual model of factors that emerged from grounded theory analysis and their impact on becoming motivated and involved with quidditch, their increased identification with the HP franchise, and the predicted purchase intentions that would derive from taking part in the sport

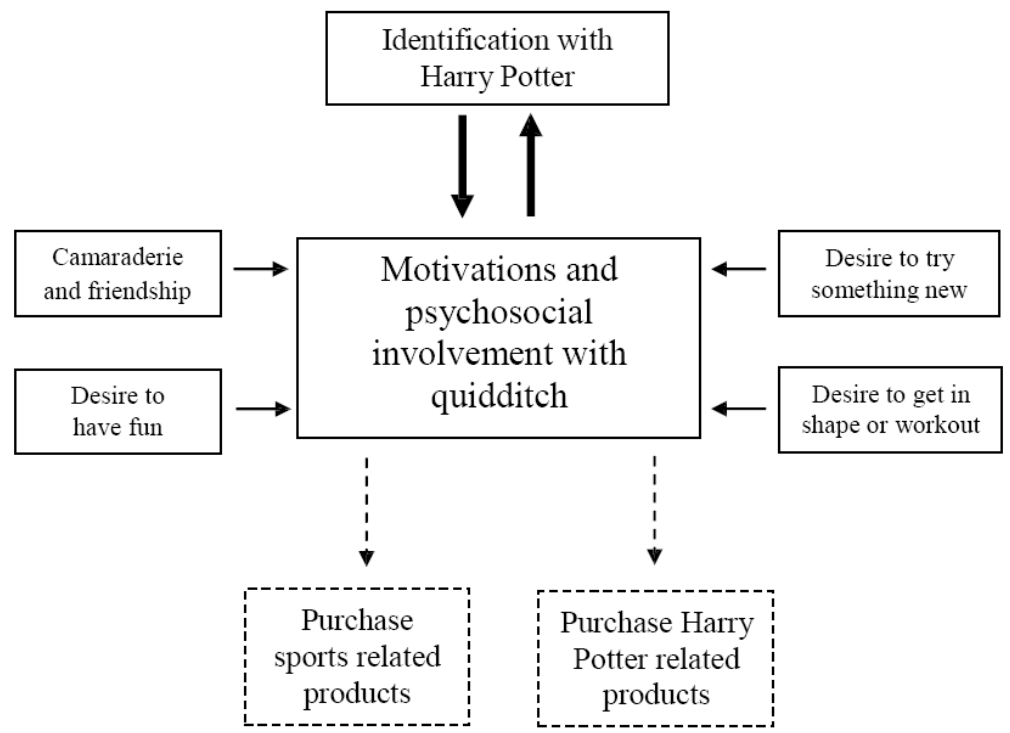

Quidditch allowed participants to fulfil social outlets which they may not have had otherwise. This could suggest that the sport has the potential, because of its ability to foster new relationships, to reach young people who normally would not partake in traditional sport. Such reliance on the sport as a social outlet emphasises psychosocial involvement, where the sport becomes a notable component of its participants' lifestyles. Furthermore, as quidditch participants became more involved with the sport, they satisfied a need to have fun and try something new, which is one of Riewald's (2003) motivations for team sport participation. Whether it was the opportunity to run around on a broom and throw 'bludgers' at opponents, or simply to mingle with fellow 'quirky' individuals, quidditch provided an outlet other extracurricular activities failed to accomplish. Recent research has also suggested that 'curiosity' can motivate and drive a person to take a deeper interest in various sporting events (Park et al., 2008, 2010, 2011). Again, this suggests that the sport was capable of reaching people who, for the most part, did not have motivation or interest in participating in traditional sports (Gould, 1987). 
Lastly, our findings revealed the sport enhanced participants' physical fitness or desire to get in shape, as several participants commented on how their involvement with the sport caused them to become physically active. As a result, this potential market segment could be more likely to make purchases that support an active lifestyle instead of buying products that sustain a sedentary lifestyle, as noted by the predicted purchase intention outcomes in Figure 1.

Merriam-Webster's Online Dictionary (2012) defines niche as, "A place, employment, status, or activity for which a person or thing is best fitted". While sports such as mixed martial arts, skateboarding, and quidditch are vastly different, and appeal to a wide demographics of participants and consumers, they seemingly appeal to their audiences' motivations and identities in very similar fashions. This highlights the importance and need for a wide variety of athletic options aimed at the various populations in society. Although the majority of participants in our study likely will not sign up for a Brazilian jiu-jitsu class in an effort to emulate UFC great Georges St-Pierre, nor will they go screaming down a half-pipe in a similar fashion as skateboarding legend Tony Hawk, their motivations to participate in sport are satisfied through quidditch.

\section{Limitations}

As all research endeavours have their limitations, we must consider several that may have potentially impacted the findings of this study. First, the potential of bias must be considered from the quidditch players that took the survey. Their positive experience and high identification with the sport could have led them to complete the survey while other athletes with a less favourable experience might have not been as willing. Also, it must be considered that quidditch is a new and evolving sport constantly amending its rulebook. It is possible that continuous rule changes and adaptations could shift the opinions of participants who are currently taking part in the sport. Lastly, the participants may have provided responses in focus groups and surveys based on what they thought researchers would want to hear. We attempted to alleviate social desirability bias by assuring confidentiality.

\section{Conclusions}

Thus, our work helps identify a niche market segment (participants of non-traditional sport) that has not been targeted previously. While quidditch may never reach a following like the NFL or become a billion dollar industry like the HP books, the participants involved repeatedly stressed their passion and enthusiasm for the sport they love. As Bennett et al. (2009) found, niche markets are ripe for sponsorship consideration and can be utilised as a platform for new commerce. By properly targeting this population, it can be argued this segment of the sports marketing industry is worth considering in regards to sponsorship, product sales, and promotions. Future directions for this line of research could include longitudinal efforts to determine if identification shifts over time and if interest in quidditch grows or wanes. Additionally, quantitative efforts could be useful to supplement the findings of this study and further define this market segment. In this particular study, it seems logical that quidditch involvement will therefore influence the consumption of the sport. As noted in Figure 1, it is predicted that participation in this 
sport will increase purchase intentions. One example of purchasing habits developed from the sport could be seen on the IQA's social media websites after Christmas in 2011. Several players proudly posted about the quidditch and HP-related gifts they received, such as one female who mentioned Santa bringing her "a quaffle, keeper gloves, and knee socks" or another male athlete excitingly posting about getting "two Alivan's brooms [an IQA vendor], gloves, and the original screenplay from Sorcerer's Stone [first book of the HP series]".

To give another monetary example involving figures generated by the sport, the Quidditch World Cup grossed $\$ 170,000$ (US) from ticket sales, merchandise, and registration fees in 2011. This was the first year tickets to the event were sold and merchandise (e.g., T-shirts, shorts, brooms, wands) was made available to the players. Public relations and marketing was conducted solely in a grassroots fashion (e.g., YouTube videos, twitter, blogs, flyers, and flash mobs in crowded areas) with a next to nothing budget. In addition to the $\$ 170,000$ that went specifically to the IQA for running the event, each team also conducted fundraising to cover costs to travel and lodge in New York city. For teams from locations such as California and Finland, this expense involved thousands of dollars. As over 1,600 quidditch players travelled to New York for this event, it can be assumed that tens of thousands of dollars were spent overall towards the desire to be part of this sport.

The implications of these observations would suggest quidditch players are a niche market highly suitable for engagement. The league and participants serve as a ripe market for sport marketers to pursue which could offer opportunities for sport sponsorship, advertising, and promotions. This could be especially relevant with this demographic of athletes because the HP books and movies have been completed, and it has yet to be determined if HP will survive the test of time (similar to a franchise like Star Wars) or if its prominence will fade over time. Brooms most likely will not be replacing baseball bats on shelves in sporting goods stores in the near future, but they, and the sport they represent, certainly can complement the industry in a positive fashion. The more people that participate in sport, the better off the sporting industry will be in the long run.

\section{References}

Andrew, D.P.S., Kim, S., O’Neal, N., Greenwell, T.C. and James, J.D. (2009) 'The relationship between spectator motivations and media and merchandise consumption at a professional mixed martial arts event', Sport Marketing Quarterly, Vol. 18, No. 4, pp.199-209.

Armstrong, K.L. (2002) 'An examination of the social psychology of blacks' consumption of sport', Journal of Sport Management, Vol. 16, No. 4, pp.267-288.

Arnett, B. and Laverie, D. (2000) 'Factors affecting fan attendance: the influence of identity salience and satisfaction', Journal of Leisure Research, Vol. 32, No. 2, pp.225-247.

Bennett, C., Henson, R. and Zhang, J. (2002) 'Action sport sponsorship recognition', Sport Marketing Quarterly, Vol. 11, No. 3, pp.174-185.

Bennett, G. and Lachowetz, T. (2004) 'Marketing to lifestyles: action sports and generation Y', Sport Marketing Quarterly, Vol. 13, No. 4, pp.239-243.

Bennett, G., Ferreira, M., Lee, J. and Polite, F. (2009) 'The role of involvement in sports and sport spectatorship in sponsor's brand use: the case of Mountain Dew and action sports sponsorship', Sport Marketing Quarterly, Vol. 18, No. 1, pp.14-24. 
Charmaz, K. (2005) 'Grounded theory in the 21st century', in Denzin, N.K. and Lincoln, Y.S. (Eds.): The SAGE Handbook of Qualitative Research, 3rd ed., pp.507-536, Sage, Thousand Oaks, CA.

Coakley, J. (2001) Sport and Society: Issues and Controversies, 7th ed., McGraw Hill, New York.

Creswell, J.W. (1998) Qualitative Inquiry and Research Design: Choosing among Five Traditions, Sage, Thousand Oaks, CA.

Day, E., Stafford, M. and Camacho, A. (1995) 'Opportunities for involvement research: a scale-development approach', Journal of Advertising, Vol. 24, No. 3, pp.69-75.

Deci, E.L. (1971) 'Effects of externally mediated rewards on intrinsic motivation', Journal of Personality and Social Psychology, Vol. 18, No. 1, pp.105-115.

Deci, E.L. and Ryan, R.M. (1985) Intrinsic Motivation and Selfdetermination in Human Behavior, Plenum, New York.

Dees, W., Hall, T., Tsuji, Y. and Bennett, G. (2010) 'Examining the effects of fan loyalty and goodwill on consumer perceptions of brands at an action sports event', Journal of Sponsorship, Vol. 4, No. 1, pp.38-50.

Ellemers, N., Spears, R. and Doosje, B. (2002) 'Self and social identity', Annual Review of Psychology, Vol. 53, No. 1, pp.161-186.

Foddy, W. (1993) Constructing Questions for Interviews and Questionnaires: Theory and Practice in Social Research, Cambridge University Press, Cambridge.

Fraser-Thomas, J., Cote, J. and Deakin, J. (2008) 'Understanding dropout and prolonged engagement in adolescent competitive sport', Psychology of Sport and Exercise, Vol. 9, No. 5, pp.645-662.

Funk, D., Ridinger, L. and Moorman, A. (2004) 'Exploring origins of involvement: understanding the relationship between consumer motives and involvement with professional sport teams', Leisure Sciences, Vol. 26, No. 1, pp.35-61.

Gladden, J.M. and Sutton, W.A. (2009) 'Marketing principles applied to sport management', in Masteralexis, L.P., Barr, C.A. and Hums, M.A. (Eds.): Principles and Practices of Sport Management, pp.42-59, Jones and Bartlett Publishers, Sudbury, MA.

Gould, D. (1987) 'Understanding attrition in children's sport', in Gould, D. and Weiss, M.R. (Eds.): Advances in Pediatric Sports Sciences, pp.61-85, Human Kinetics, Champaign, IL.

Gould, D. and Horn, T. (1984) 'Participation motivation in young athletes', in Silva, J.M. and Weinberg, R.S. (Eds.): Psychological Foundations of Sport, pp.359-370, Human Kinetics, Champaign, IL.

Gould, D., Dieffenbach, K. and Moffett, A. (2002) 'Psychological characteristics and their development in Olympic champions', Journal of Applied Sport Psychology, Vol. 14, No. 3, pp.172-204.

Goulding, C. (1998) 'Grounded theory: the missing methodology on the interpretivist agenda', Qualitative Marketing Research: An International Journal, Vol. 1, No. 1, pp.50-57.

Goulding, C. (2001) 'Grounded theory: a magical formula or a potential nightmare', The Marketing Review, Vol. 2, No. 1, pp.21-34.

Greenhalgh, G.P., Simmons, J.M., Hambrick, M.E. and Greenwell, T.C. (2011) 'Spectator support: examining the attributes that differentiate niche from mainstream sport', Sport Marketing Quarterly, Vol. 20, No. 1, pp.41-52.

Havitz, M. and Mannell, R. (2005) 'Enduring involvement, situational involvement, and flow in leisure and non-leisure activities', Journal of Leisure Research, Vol. 37, No. 2, pp.152-177.

Hewstone, M., Rubin, M. and Willis, H. (2002) 'Intergroup bias', Annual Review of Psychology, Vol. 53, No. 1, pp.575-595.

Hirschman, E.C. and Thompson, C. (1997) 'Why media matter: toward a richer understanding of consumers' relationships with advertising and mass media', The Journal of Advertising, Vol. 26, No. 1, pp.43-60. 
Houston, H.R. and Venkatesh, A. (1996) 'The health-care consumption patterns of Asian immigrants: grounded theory implications for consumer acculturation theory', Advances in Consumer Research, Vol. 23, pp.418-423.

International Quidditch Association (IQA) (2011) Mission statement, [online] http://www.internationalquidditch.org/mission (accessed 10/01/2011).

Iwasaki, Y. and Havitz, M. (1998) 'A path analytic model of the relationships between involvement, psychological commitment, and loyalty', Journal of Leisure Research, Vol. 30, No. 2, pp.256-280.

Kerstetter, D.L. and Kovich, G.M. (1997) 'An involvement profile of Division I women's basketball spectators', Journal of Sport Management, Vol. 11, No. 3, pp.234-249.

Kim, S., Andrew, D.P.S. and Greenwell, T.C. (2009) 'An analysis of spectator motives and media consumption behavior in an individual combat sport: cross-national differences between American and South Korean mixed martial arts fans', International Journal of Sports Marketing \& Sponsorship, Vol. 10, No. 2, pp.157-170.

Kim, S., Greenwell, C., Andrew, D.P.S., Lee, J. and Mahony, D.F. (2008) 'An analysis of spectator motives in an individual combat sport: a study of mixed martial arts fans', Sport Marketing Quarterly, Vol. 17, No. 2, pp.109-119.

Kim, S., Scott, D. and Crompton, J. (1997) 'An exploration of the relationships among social psychological involvement, behavioral involvement, commitment, and future intentions in the context of birdwatching', Journal of Leisure Research, Vol. 29, No. 3, pp.320-334.

Krueger, R.A. and Casey, M.A. (2009) Focus Groups: A Practical Guide for Applied Research, London, Sage.

Lincoln, Y.S. and Guba, E.G. (1985) Naturalistic Inquiry, Sage, Beverly Hills, CA.

Merriam-Webster's Online Dictionary (2012) 'Definition of niche', [online] http://www.merriamwebster.com/dictionary/niche (accessed 10/01/2011).

Milne, G.R. and McDonald, M.A. (1999) Sport Marketing: Managing the Exchange Process, Jones and Bartlett, Sudbury, MA.

Milne, G.R., McDonald, M.A., Sutton, W.A. and Kashyap, R. (1996) 'A niche-based evaluation of sport participation patterns', Journal of Sport Management, Vol. 10, No. 4, pp.417-434.

Miloch, K. and Lambrecht, K.W. (2006) 'Consumer awareness of sponsorship at grassroots sport events', Sport Marketing Quarterly, Vol. 15, No. 3, pp.147-154.

Mulin, B.J., Hardy, S. and Sutton, W. (2007) Sport Marketing, Human Kinetics, Champaign, IL.

Noble, S.M., Haytko, D.L. and Phillips, J. (2009) 'What drives college-age generation Y consumers?', Journal of Business Research, Vol. 62, No. 6, pp.617-628.

Park, S., Andrew, D.P.S. and Mahony, D.F. (2008) 'Exploring the relationship between trait curiosity and initial interest in sport spectatorship', International Journal of Sport Management, Vol. 9, No. 3, pp.286-303.

Park, S., Mahony, D.F. and Greenwell, T.C. (2010) 'The measurement of sport fan exploratory curiosity', Journal of Sport Management, Vol. 24, No. 4, pp.434-455.

Park, S., Mahony, D.F. and Kim, Y.K. (2011) 'The role of sport fan curiosity: a new conceptual approach to the understanding of sport fan behavior', Journal of Sport Management, Vol. 25, No. 1, pp.46-56.

Paul, P. (2001) 'Getting inside Gen Y', American Demographics, Vol. 23, No. 9, pp.42-49.

Richins, M., Bloch, P. and McQuarrie, E. (1992) 'How enduring and situational involvement combine to create involvement responses', Journal of Consumer Psychology, Vol. 1, No. 2, pp.143-153.

Riewald, S.T. (2003) 'Strategies to prevent dropout from youth athletics', New Studies in Athletics, Vol. 18, No. 3, pp.21-26.

Roberts, G.C. (2001) 'Understanding the dynamics of motivation in physical activity: the influence of achievement goals and motivational processes', in Roberts, G.C. (Ed.): Advances in Motivation in Sport and Exercise, pp.1-50, Human Kinetics, Champaign, IL. 
Skill, E. and Osteras, J. (2011) 'What does sport mean to you? Fun and other preferences for adolescents' sport participation', Critical Public Health, Vol. 21, No. 3, pp.359-372.

Stone, R. (1984) 'The marketing characteristics of involvement', Advances in Consumer Research, Vol. 11, No. 1, pp.210-215.

Strauss, A. and Corbin, J. (1990) Basics of Qualitative Research: Grounded Theory Procedures and Techniques, Sage, Newbury Park, CA.

Tajfel, H. and Turner, J.C. (1986) 'Social identity theory of intergroup behaviour', in Austin, W. and Worchel, S. (Eds.): Psychology of Intergroup Relations, 2nd ed., pp.33-47, Nelson-Hall, Chicago.

Vallerand, R.J. (1997) 'Toward a hierarchical model of intrinsic and extrinsic motivation', in Zanna, M. (Ed.): Advances in Experimental Social Psychology, pp.271-360, Academic Press, New York.

Vallerand, R.J. (2007) 'Intrinsic and extrinsic motivation in sport and physical activity: a review and a look at the future', in Tenenbaum, G. and Eklund, R.E. (Eds.): Handbook of Sport Psychology, 3rd ed., pp.49-83, Wiley, New York.

Vallerand, R.J., Blais, M.R., Briére, N.M. and Pelletier, L.G. (1989) 'Construction et validation de 1 'Echelle de Motivation en Education [Construction and validation of the academic motivation scale]', Canadian Journal of Behavioral Sciences, Vol. 21, pp.323-349.

Wakefield, K.L. (1995) 'The pervasive effects of social influence on sporting event attendance', Journal of Sport and Social Issues, Vol. 19, No. 4, pp.335-351.

Wilson, P.M., Mack, D.E. and Grattan, K.P. (2008) 'Understanding motivation for exercise: a self-determination theory perspective', Canadian Psychology, Vol. 49, No. 3, pp.250-256. 